\title{
Є. Є. ЧАЙКОВСЬКА
}

\section{КОНТРОЛЬ ПРАЦЕЗДАТНОСТІ КОГЕНЕРАЦЙНОЇ СИСТЕМИ НА ПЕЛЕТНОМУ ПАЛИВІ}

\begin{abstract}
АНОтАЦІЯ Запропонована інтегрована система підтримки температури місцевої води при вимірюванні температури газів та температури зворотної води на вході в теплообмінник другого контуру когенераційної системи. Прийняття рімень на зміну кількості пластин теплообмінника надає можливість підтримувати співвідношення виробництва електричної енергї та теплоти при використанні зміни частоти обертання електродвигуна повітряного вентилятора щуодо зміни витрати повітря, щуо подається на підігрів, для сушки деревини. Такий підхід дозволяє, наприклад, в умовах функціонування когенераційної системи потужністю 115 кВт знизити собівартість виробленої енергії до 20-30\%.
\end{abstract}

Ключові слова: когенераційна установка, пелетне паливо, контроль працездатності, прийняття рішень.

\section{E. CHAIKOVSKAYA}

\section{CONTROL WORKING ABILITY OF THE COGENERATION SYSTEM ON PELLET FUEL}

ABSTRACT The proposed architecture of the cogeneration system, which is the basis integrated dynamic subsystem cogeneration plant, heat exchanger secondary circuit heating local water, drying plant, heat exchanger heating the air, the air blower and blocks a charge, discharge, assessment of functional performance that are agreed upon interaction with dynamic subsystem. Complex mathematical modeling of the dynamics of the second circuit of the heat exchanger cogeneration system provides the ability to define tolerances to temperature change local water levels established for the operation. A complex mathematical and logical modeling efficiency cogeneration control system for obtaining functional evaluation of local water temperature changes. Block diagram of temperature maintenance of local water-level decisionmaking to determine the final information on the decision to change the number plates of the heat exchanger by comparing the temperature of the gases at the inlet to the heat exchanger of the second circuit cogeneration system, measured from the reference value. The proposed integrated system of support for local water temperature for measuring the temperature of gases and return water temperature at the inlet to the heat exchanger of the second circuit of the cogeneration system. Deciding to change the number plate heat exchanger allows to maintain the ratio of production of electricity and heat using changes of rotational speed of the electric fan of air to change the air flow supplied to the heater for drying wood. This approach allows, for example, in terms of functioning cogeneration system capacity of $115 \mathrm{~kW}$ reduce the cost of energy produced (20-30) \%.

Keywords: cogeneration plant, pellet fuel, control of operation, making decisions.

\section{Вступ}

Реалізація виробленої енергії за «зеленим тарифом» при використанні біопалива як відновлюваного джерела енергії є однією з переваг когенераційних технологій щодо виробництва електричної енергії та теплоти від одного первинного джерела енергії $[1,2]$. Але непостійність споживання виробленої енергії потребує удосконалення систем підтримки співвідношення виробництва електричної енергї та теплоти в умовах ресурсо та енергозбереження [2]. При виробництві пелетного палива витрати на сушку деревини складають до 25 \% від загальних витрат. Вміст вологи не повинен перевищувати 10-12 \%, а сира деревина може містити близько $50 \%$ води. В роботі [3], наприклад, визначено перевагу механічної активації матеріалу, що висушується, але за рахунок додаткових витрат на електричну енергію. В роботі [4] визначено, що на якість сушки впливають конструктивні параметри сушильної камери, але оцінка проведена при вимірюванні параметрів сушки в сушильній камері, що у зв'язку із складністю вимірів має недостовірне використання. В роботі [5] визначено вплив режимних параметрів сушки на якість сушки, але без узгодження температурного та аеродинамічного режимів сушіння матеріалу. В роботах $[6,7]$ видані рекомендації щодо інтенсифікації теплообміну в сушильній камері, але без можливості їх використання в реальних умовах функціонування сушильної установки. Для підтримки потужності сушки деревини використовують діагностичні системи, що базуються на вимірюванні температури повітря та його вологості в сушильній камері при вимірюванні вологості деревини. Складність вимірів та не можливість використання у єдності може привести до незворотного накопичення вологи деревиною чи припинення процесу сушки $[8,9]$. У зв'язку з цим, в роботі [10] запропонована технологія функціонування сушильної установки у складі когенераційної системи щодо виробництва пелетного палива, яка дозволяє підтримувати підігрів повітря в теплообміннику, що входить до ії складу, при вимірюванні температури повітря на виході із сушильної камери. Використання інтегрованої системи оцінки зміни вологовмісту повітря в сушильній камері, здобутої на основі математичного та логічного моделювання у складі когенераційної системи, надає можливість виконувати зміну витрати повіт-

(C) Є. Є. Чайковська, 2017 
ря, що подається на підігрів, на основі зміни частоти обертання електродвигуна повітряного вентилятора та забезпечувати своєчасну подачу висушеної деревини та завантаження свіжого матеріалу. У зв'язку із зміною споживання електричної енергії на сушку деревини щодо зміни частоти обертання повітряного вентилятора необхідно виконувати підтримку температури місцевої води у якості теплоносія, що гріє, для підігріву повітря впродовж терміну сушки щодо забезпечення співвідношення виробництва електричної енергії та теплоти. Цілодобове ж функціонування пелетних установок дозволяє розширити термін функціонування когенераційних систем щодо додаткового вироблення енергії при гарантованому забезпеченні пелетним паливом та встановленому точному терміну відвантаження висушеної деревини та завантаження свіжого матеріалу.

\section{Мета роботи}

Мета роботи - розробка інтегрованої системи підтримки температури місцевої води другого контуру когенераційної системи щодо підігріву повітря для сушки деревини в умовах зміни частоти обертання електродвигуна повітряного вентилятора.

Поставлена мета може бути досягнена при виконанні таких задач:

- обгрунтувати необхідність підтримки співвідношення виробництва електричної енергії та теплоти в умовах функціонування когенераційної системи на пелетному паливі при використанні зміни частоти обертання електродвигуна повітряного вентилятора щодо зміни витрати повітря, що подається на підігрів, на сушку деревини 3 використанням теплоносія, що гріє, від другого контуру когенераційної системи;

- запропонувати архітектуру когенераційної системи, що має у своєму складі основу - динамічну підсистему, яка включає когенераційну установку, теплообмінник другого контуру підігріву місцевої води, сушильну установку, теплообмінник підігріву повітря, повітряний вентилятор та блоки розряду, заряду, оцінки функціональної ефективності, що знаходяться в узгодженій взаємодії з динамічною підсистемою;

- виконати комплексне математичне моделювання динаміки теплообмінника другого контуру когенераційної системи при вимірюванні температури газів та температури зворотної води на вході в теплообмінник;

- запропонувати структурну схему для здобуття еталонної інформації на основі комплексного математичного моделювання у складі когенераційної системи;

- виконати комплексне математичне та логічне моделювання щодо контролю працездатності когенераційної системи на основі розробленої структурної схеми;

- розробити структурну схему та виконати комплексне математичне та логічне моделювання щодо прийняття рішень на зміну поверхні теплообміну теплообмінника другого контуру когенераційної системи;

- виконати комплексне логічне моделювання щодо ідентифікації нових умов функціонування когенераційної системи на основі розробленої схеми;

- розробити інтегровану систему підтримки температури місцевої води при зміні споживання електричної енергії, що обумовлено зміною частоти обертання електродвигуна повітряного вентилятора;

- оцінити практичну значущість здобутих результатів.

\section{Контроль працездатності когенераційної системи на пелетному паливі}

Для здобуття еталонної та функціональної інформації щодо прийняття рішень на підтримку температури місцевої води щодо підігріву повітря запропонована архітектура когенераційної системи, основою якої $є$ інтегрована динамічна підсистема - (когенераційна установка, теплообмінник другого контуру підігріву місцевої води, сушильна установка, теплообмінник підігріву повітря, повітряний вентилятор) та блоки, заряду, розряду, оцінки функціональної ефективності, що знаходяться в узгодженій взаємодії 3 динамічною підсистемою (рис. 1).

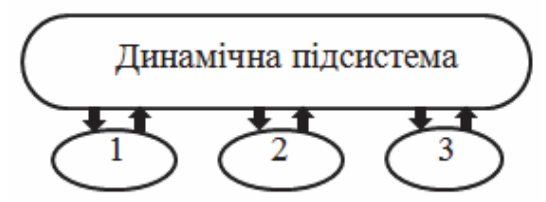

Рис. 1 - Архітектура когенераційної системи: динамічна підсистема (когенераційна установка, теплообмінник другого контуру підігріву місцевої води, сушильна установка, теплообмінник підігріву повітря, повітряний вентилятор; 1 - блок розряду; 2 - блок заряду; 3 - блок оцінки функиіональної ефективності

Математичне обгрунтування архітектури когенераційної системи:

$$
C S=\left\{\begin{array}{l}
\left.\left[D\left(P(\tau)\left\langle x_{0}(\tau), x(\tau), f(\tau), K(\tau), y(\tau), d(\tau)\right)\right\rangle, R(\tau)\right], P(\tau)\right), \\
Z(\tau),\left(P_{i}(\tau)\left\langle x_{1}(\tau), f_{i}(\tau), K_{i}(\tau), y_{i}(\tau)\right\rangle\right)
\end{array}\right\},
$$

де $C S$ - когенераційна система; $D$ - динамічна підсистема (когенераційна установка, теплообмінник другого контуру підігріву місцевої води, сушильна установка, теплообмінник підігріву повітря, повітряний вентилятор); $P$ - властивості елементів когенераційної системи; $x$ - впливи; $f$ - параметри, 
що діагностуються; $K$ - коефіцієнти математичного опису; $y$ - вихідні параметри; $d$ - динамічні параметри; $R$ - логічні відносини в $C S ; \tau-$ час, с. Iндекси: $i$ - число елементів когенераційної системи; $0,1,2$ - початковий стаціонарний режим, зовнішній, внутрішній характер впливів.

Основою для підтримки температури місцевої води щодо здобуття як гранично припустимої, так і функціональної інформації $є$ математична модель динаміки теплообмінника другого контуру підігріву місцевої води, що оцінює зміну температури води як у часі, так і вздовж просторової координати осі теплообмінника, що співпадає 3 напрямком потоку руху середовища. Передатна функція за каналом: «температура місцевої води - температура газів» має такий вид:

$$
\begin{gathered}
W_{t-\vartheta_{1}}=\frac{K_{3} \varepsilon\left(1-L_{3}^{*}\right)}{\left(T_{\mathrm{B}} S+1\right) \beta-1}\left(1-e^{-\gamma \xi}\right), \\
\text { де } K_{3}=\frac{m\left(\theta_{0}-\sigma_{0}\right)}{G_{30}}, \varepsilon=\frac{\alpha_{30} h_{30}}{\alpha_{\mathrm{B} 0} h_{\mathrm{B} 0}}, L_{3}^{*}=\frac{1}{L_{3}+1}, \\
L_{3}=\frac{G_{3} C_{3}}{\alpha_{30} h_{30}}, T_{\mathrm{B}}=\frac{g_{\mathrm{B}} C_{\mathrm{B}}}{\alpha_{\mathrm{B} 0} h_{\mathrm{B} 0}} ; \beta=T_{\mathrm{M}} S+\varepsilon^{*}+1, \\
T_{\mathrm{M}}=\frac{g_{\mathrm{M}} C_{\mathrm{M}}}{\alpha_{\mathrm{B} 0} h_{\mathrm{B} 0}}, \varepsilon^{*}=\varepsilon\left(1-L_{3}^{*}\right), \gamma=\frac{\left(T_{\mathrm{B}} S+1\right) \beta-1}{\beta}, \\
\xi=\frac{z}{L_{\mathrm{B}}}, L_{\mathrm{B}}=\frac{G_{\mathrm{B}} C_{\mathrm{B}}}{\alpha_{\mathrm{B} 0} h_{\mathrm{B} 0}},
\end{gathered}
$$

де $t, \sigma, \theta$ - температура місцевої води, газів, поділяючої стінки, К, відповідно; $G$ - витрата речовини, кг/с; $C$ - питома теплоємність, кДж/(кг·К); $\alpha-$ коефіцієнт тепловіддачі, кВт/( $\left.{ }^{2} \cdot \mathrm{K}\right) ; h$ - питома поверхня, $\mathrm{M}^{2} / \mathrm{M} ; g$ - питома маса речовини, кг/м; $z-$ координата довжини теплообмінника, м; $T_{\text {в }}, T_{\text {м }}$ постійні часу, що характеризують теплову акумулюючу здатність робочого тіла, метала, с; $m$ - показник залежності коефіцієнта тепловіддачі від витрати; $S$ - параметр перетворення Лапласа. Індекси: в - внутрішній потік - місцева вода, м - металева стінка, з - зовнішній потік - гази; 0, 1 - початкові умови, вхід в теплообмінник, відповідно.

Після математичної обробки здобутої функції виділено дійсну частину, $O(\omega)$

$$
O(\omega)=\frac{\left(L_{1} A_{1}\right)+\left(M_{1} B_{1}\right) K_{3} \varepsilon\left(1-L_{3}^{*}\right)}{A_{1}^{2}+B_{1}^{2}} .
$$

Для одержання коефіцієнтів у складі дійсної частини $O(\omega)$ здобуто такі вирази:

$$
\begin{gathered}
A_{1}=\varepsilon^{*}-T_{\mathrm{B}} T_{\mathrm{M}} \omega^{2}, A_{2}=\varepsilon^{*}+1, \\
B_{1}=T_{\mathrm{B}} \varepsilon \omega-T_{\mathrm{B}} \omega+T_{\mathrm{M}} \omega, B_{2}=T_{\mathrm{M}} \omega, \\
C_{1}=\frac{A_{1} A_{2}+B_{1} B_{2}}{A_{2}^{2}+B_{2}^{2}}, D_{1}=\frac{A_{2} B_{1}+A_{1} B_{2}}{A_{2}^{2}+B_{2}^{2}} \\
L_{1}=1-e^{-\zeta C_{1}} \cos \left(-\xi D_{1}\right), M_{1}=-e^{-\zeta C_{1}} \sin \left(-\xi D_{1}\right) .
\end{gathered}
$$

Температура поділяючої стінки $\theta$, що входить до складу коефіцієнта $K_{3}$

$$
\theta=\left[\frac{\alpha_{\mathrm{B}}\left(\sigma_{1}+\sigma_{2}\right)}{2}+\frac{A\left(t_{1}+t_{2}\right)}{2}\right] /\left(\alpha_{\mathrm{B}}+A\right),
$$

де $\alpha$ - коефіцієнт тепловіддачі, кВт/( $\left.\mathrm{M}^{2} \cdot \mathrm{K}\right) ; \sigma_{1}, \sigma_{2}-$ температура газів на вході та на виході з теплообмінника, $\mathrm{K} ; t_{1}, t_{2}$ - температура місцевої води на вході та на виході з теплообмінника, К.

$$
A=\frac{1}{\frac{\delta_{\mathrm{M}}}{\lambda_{\mathrm{M}}}+\frac{1}{\alpha_{3}}},
$$

де $\delta$ - товщина стінки теплообмінника, м; $\lambda-$ теплопровідність металу стінки теплообмінника, кВт/(м·K).

3 використанням інтеграла переходу з частотної області до області часу зміна температури місцевої води як за часом, так і вздовж просторової координати осі теплообмінника має такий вид

$$
t(\tau, z)=\frac{1}{2 \pi} \int_{0}^{\infty} O(\omega) \sin (\tau \omega / \omega) d \omega .
$$

Для здобуття еталонної оцінки зміни температури місцевої води розроблено структурну схему, що представлена для вихідних даних когенераційної системи 3 використанням сушильної установки продуктивністю 680 кг/добу деревини (рис. 2).

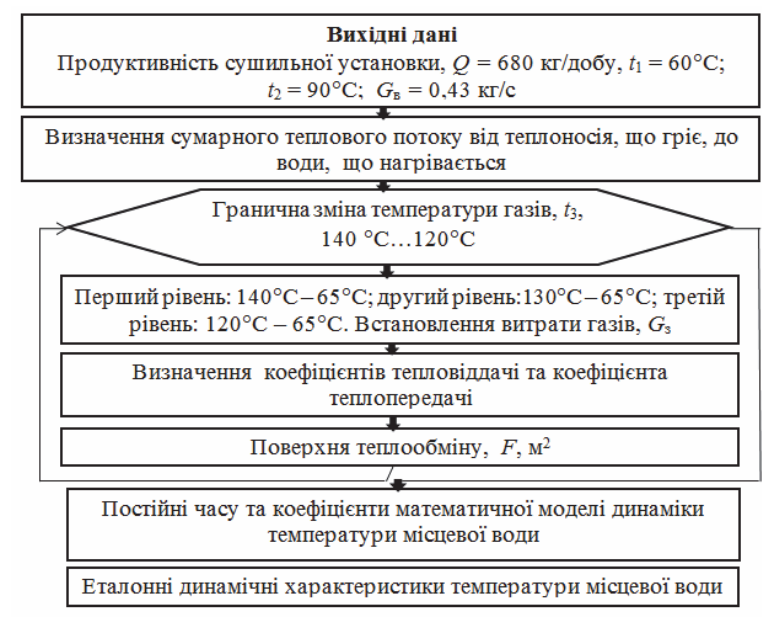

Рис. 2 - Структурна схема комплексного математичного моделювання теплообмінника другого контуру підігріву місиевої води: $G_{3}, G_{6}-$ витрата газів, місиевої води, кг/с, відповідно; $t_{1}, t_{2}$ - температура місиевої води на вході в теплообмінник та на виході з теплообмінника, $K$, відповідно; $t_{3}-$ те-

мпература газів на вході в теплообмінник, $K$

В межах запропонованої циклічної структури щодо підтримки температури підігріву місцевої води $360{ }^{\circ} \mathrm{C}$ до $90{ }^{\circ} \mathrm{C}$ при граничній зміні температури газів на вході в теплообмінник $-140 \ldots 120^{\circ} \mathrm{C}$ встановлено наступні рівні функціонування когенераційної системи відповідно зміні температури газів на вході в теплообмінник: перший рівень: $140 \ldots 65^{\circ} \mathrm{C}$; другий рівень: $130 \ldots 65^{\circ} \mathrm{C}$; третій рі- 
вень: $120 \ldots .65^{\circ} \mathrm{C}$. Встановлені рівні функціонування при температурі газів на виході із теплообмінника $-65^{\circ} \mathrm{C}$ відповідають зміні поверхні теплообміну теплообмінника щодо зміни кількості пластин: 36, 44, 52 та зміні витрати газів: 0,69 кг/с, 0,79 кг/с, 0,94 кг/с, відповідно. В табл. 1-3 представлені результати комплексного математичного моделювання динаміки теплообмінника другого контуру підігріву місцевої води.

Таблиця 1 - Параметри теплообміну в теплообміннику другого контуру когенераційної системи

\begin{tabular}{|c|c|c|c|}
\hline \multirow{2}{*}{$\begin{array}{c}\text { Рівні } \\
\text { функціонування }\end{array}$} & $\begin{array}{c}\mid 3 \\
\alpha_{3}, \\
\mathrm{BT} /\left(\mathrm{M}^{2} \cdot \mathrm{K}\right)\end{array}$ & $\begin{array}{c}\alpha_{\mathrm{B}}, \\
\mathrm{B} \mathrm{T} /\left(\mathrm{M}^{2} \cdot \mathrm{K}\right)\end{array}$ & $\begin{array}{c}k, \\
\mathrm{BT}^{2} /\left(\mathrm{M}^{2} \cdot \mathrm{K}\right)\end{array}$ \\
\hline Перший рівень & 3595,7 & 1027,9 & 745,7 \\
\hline Другий рівень & 3132,8 & 960,7 & 732,0 \\
\hline Третій рівень & 2754,7 & 922,0 & 698,0 \\
\hline
\end{tabular}

Примітка: $\alpha_{3}$ - коефіиієнт тепловіддачі від теплоносія, щзо гріє, до стінки теплообмінника, $\mathrm{Bm} /\left(\mathrm{M}^{2} \cdot K\right) ; \alpha_{6}-$ коефіиієнт тепловіддачі від стінки теплообмінника до місиевої води, $\mathrm{Bm} /\left(\mathrm{M}^{2} \cdot K\right) ; k-$ коефіиієнт теплопередачі, $\mathrm{Bm} /\left(\mathrm{M}^{2} \cdot K\right)$.

Таблиця 2 - Постійні часу математичної моделі динаміки температури місцевої води

\begin{tabular}{|c|c|c|}
\hline Рівні функціонування & $T_{\mathrm{B}}, \mathrm{c}$ & $T_{\mathrm{M}}, \mathrm{c}$ \\
\hline Перший рівень & 4,67 & 1,52 \\
\hline Другий рівень & 4,79 & 1,62 \\
\hline Третій рівень & 4,99 & 1,69 \\
\hline
\end{tabular}

Таблиця 3 - Коефіцієнти математичної моделі динаміки температури місцевої води

\begin{tabular}{|c|c|c|c|c|c|}
\hline $\begin{array}{c}\text { Рівні } \\
\text { функціонування }\end{array}$ & $L_{3}, \mathrm{M}$ & $L_{\mathrm{B}}, \mathrm{M}$ & $L_{3}{ }^{*}$ & $\zeta$ & $\varepsilon$ \\
\hline Перший рівень & 11,4 & 114,9 & 0,08 & 0,67 & 4,07 \\
\hline Другий рівень & 15,1 & 123,0 & 0,06 & 0,76 & 3,79 \\
\hline Третій рівень & 20,3 & 128,2 & 0,05 & 0,78 & 3,47 \\
\hline
\end{tabular}

Представлена структурна схема (рис. 2), що базується на комплексному математичному моделюванні теплообмінника другого контуру когенераційної системи надає можливість на основі визначення параметрів теплообміну в теплообміннику та з використанням здобутих постійних часу та коефіцієнтів, що входять до складу математичної моделі динаміки температури місцевої води, визначити гранично припустиму зміну температури місцевої води для встановлених рівнів функціонування (рис. 3).

Для контролю працездатності когенераційної системи запропоновано структурну схему комплексного математичного та логічного моделювання 3 використанням метода графа причиннонаслідкових зв'язків [2, 10] щодо здобуття функціональної інформації (рис. 4).

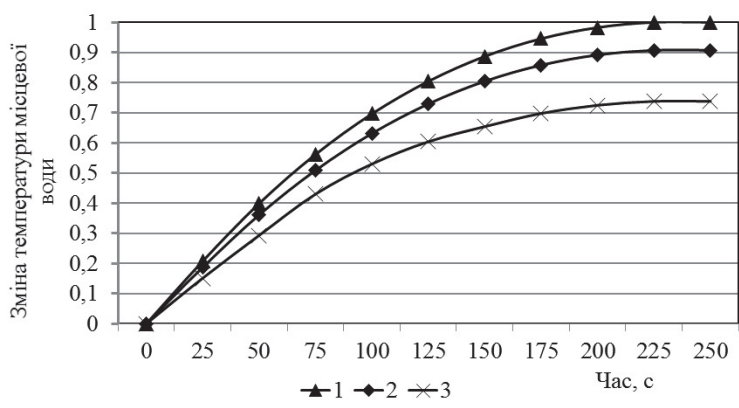

Рис. 3 - Допуски на граничну зміну температури місиевої води: 1, 2, 3 - перший, другий, третій рівні функціонування, відповідно

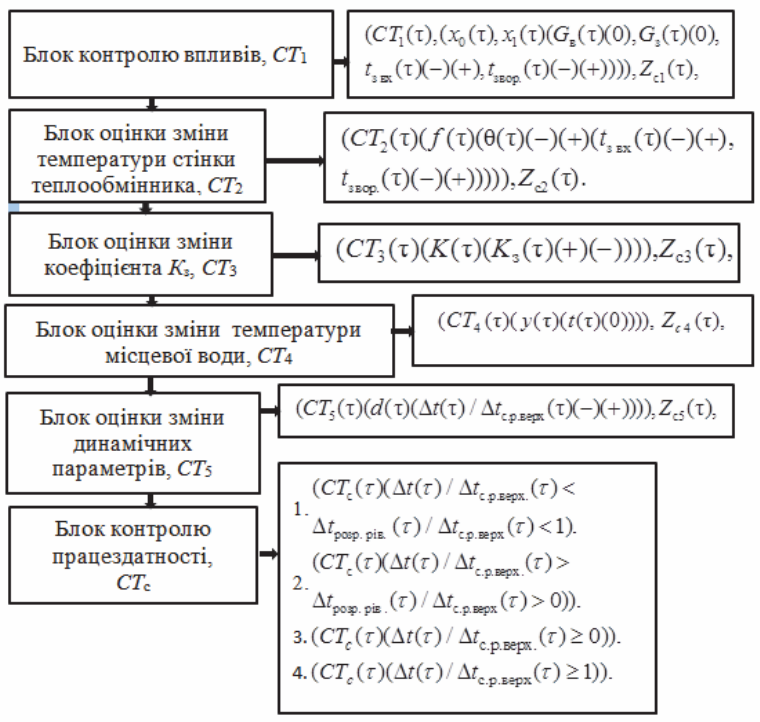

Рис. 4 - Структурна схема комплексного математичного та логічного моделювання: СТ - контроль подіі; $Z$-логічні відносини; $d$-динамічні параметри; $t$-температура місиевої води, $K$; $t_{3}$ - температура газів, $K$; $x$ - впливи; $f$-параметри, щьо діагностуються; $y$-вихідні параметри;

$K$ - коефіиіснти математичного опису;

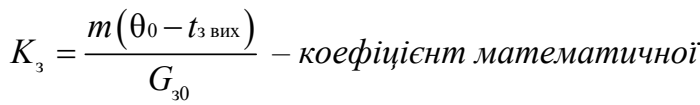
моделі динаміки теплообмінника охолодження газів, де, $\theta$-температура стінки теплообмінни$\kappa а, K$, відповідно; $G$ - витрата теплоносіїв, кг/c; Індекси: с - контроль працездатності; вх., вих.вхід, вихід газів; звор - зворотна вода; з-гази; вмісчева вода; с.р.верх. - стале розрахункове значення параметра першого рівня функціонування; розр. рів. - розрахункове значення параметра рівня функціонування 0, 1, 2- початковий стаціонарний режим, зовнішні, внутрішні впливи; 3 -коефіцієнти рівнянь динаміки; 4 -суттєві параметри, щуо діагностуються; 5 - динамічні параметри 


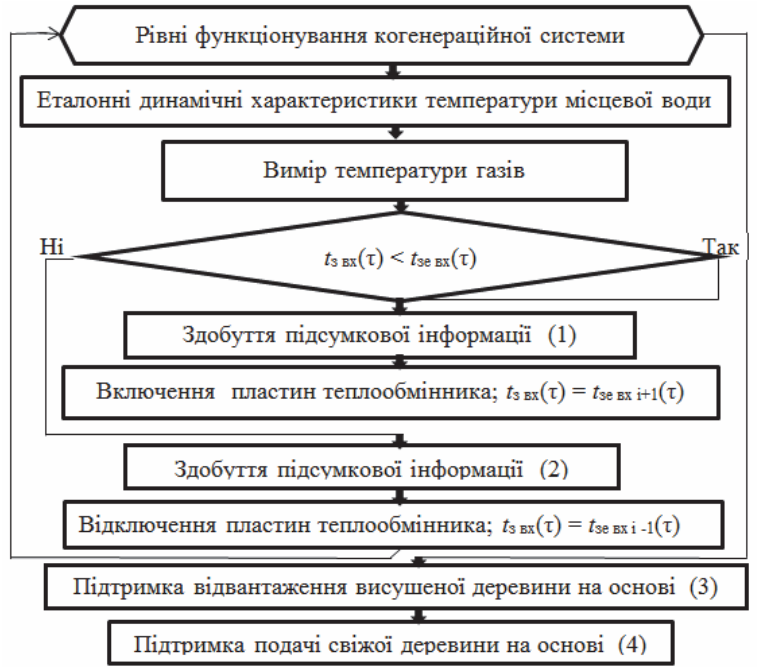

Рис. 5 - Структурна схема підтримки температури місиевої води на рівні прийняття рішень, де $t_{36}, t_{\text {зе вх }}$ - функиіональна та еталонна температура газів на вході в теплообмінник підігріву місчевої води, $K$; $i$-число рівнів функціонування; $\tau-4 a c, c$

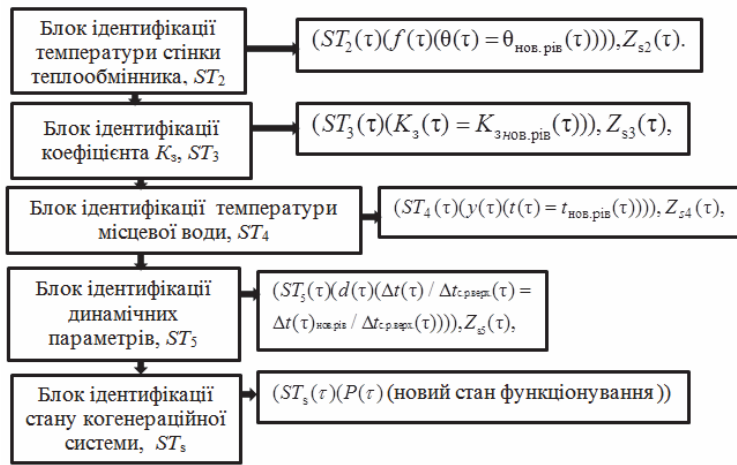

Рис. 6-Структурна схема логічного моделювання ідентифікаиії стану когенераиійної системи:

$S T$ - ідентифікація стану; $P$ - властивості когенераційної системи. Індекси: $s$ - стан; нов. рів. новий рівень функціонування; 2 - внутрішні параметри, щзо діагностуються

При безперервному вимірюванні температури газів на вході в теплообмінник підігріву місцевої води, що порівнюються з еталонним значенням рівня функціонування, з використанням логічної структури в межах циклу запропоновано виконувати включення чи відключення пластин теплообмінника щодо підтримки температури місцевої води на основі здобутої інформаційної оцінки (1), (2), відповідно (рис. 5).

Підтвердження правильності прийнятих рішень виконано на основі запропонованої структурної схеми ідентифікації стану когенераційної системи (рис. 6), що розроблена на основі графа причинно-наслідкових зв'язків $[2,10]$.

Так, наприклад, при зниженні температури газів на вході з теплообмінник $3140{ }^{\circ} \mathrm{C}$ до $134{ }^{\circ} \mathrm{C}$ та зниженні температури зворотної води $360^{\circ} \mathrm{C}$ до $56^{\circ} \mathrm{C}$, що обумовлено зменшенням частоти обертання двигуна повітряного вентилятора щодо зміни витрати повітря, що подається на підігрів 3 1,8 кг/с до 1,68 кг/с [10], необхідно прийняти рішення на зміну кількості пластин теплообмінника з 36 на 44 щодо входження в допуск другого рівня функціонування для підтримки температури місцевої води, що подається на підігрів повітря (рис. 7).

Здобуття ж підсумкової інформації (3) при температурі газів на вході в теплообмінник $120^{\circ} \mathrm{C}$, а температурі зворотної води $-55^{\circ} \mathrm{C}$ свідчить про завершення процесу сушки деревини та надає можливість 3 використанням інформаційної оцінки (4) входження в допуск першого рівня функціонування другого контуру когенераційної системи щодо зміни кількості пластин теплообмінника 352 до 36 для підтримки підігріву повітря щодо сушки завантаженої свіжої деревини (рис. 8).

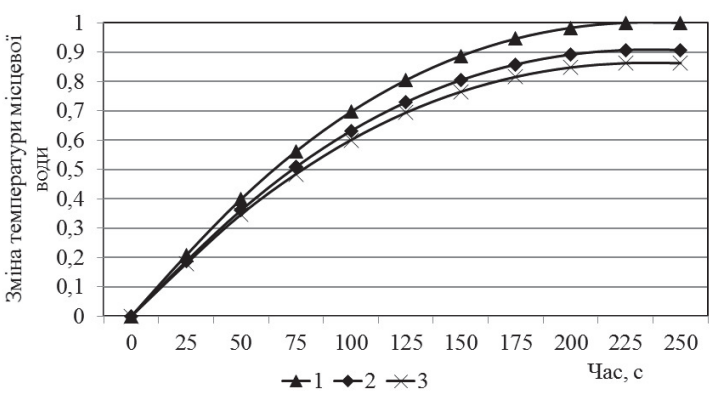

Рис. 7 - Контроль працездатності та підтвердження стану когенераційної системи при переході з першого рівня функиіонування на другий рівень: 1-допуск першого рівня функиіонування; 2 - допуск другого рівня функціонування та ідентифікація нових умов функиіонування щзодо пере-

ходу з першого рівня функиіонування на другий рівень; 3 - прийняття рішення щзодо зміни кількості пластин з 36 на 44

На основі запропонованої архітектури когенераційної системи (рис. 1) та розроблених структурних схем (рис. 2, 4-6), що апробовані для підтримки функціонування другого контуру когенераційної системи для фіксованого інтервалу часу, розроблено інтегровану систему підтримки температури місцевої води при безперервному вимірюванні температури газів на вході в теплообмінник та температури зворотної води (рис. 9). Оцінка зміни температури місцевої води дозволяе приймати рішення на зміну поверхні теплообміну теплообмінника впродовж терміну сушки деревини та підтримувати відвантаження висушеної деревини та завантаження свіжого матеріалу. 


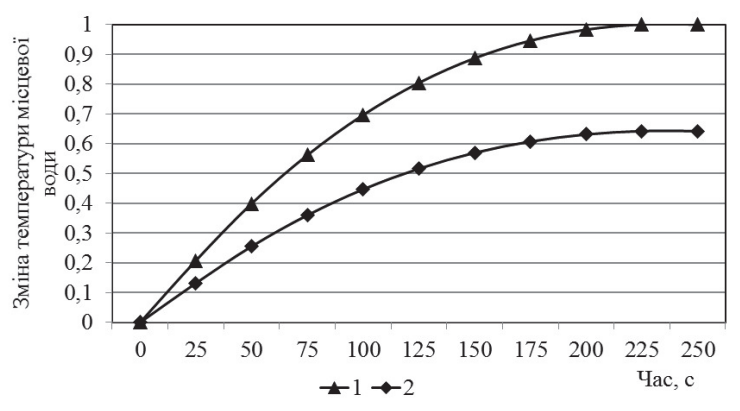

Рис. 8 - Контроль працездатності та підтвердження стану когенераційної системи щзодо зміни режимних умов функціонування: 1 - допуск першого рівня функціонування та підтримка завантаження свіжої сировини; 2 - підтримка відвантаження висушеної деревини

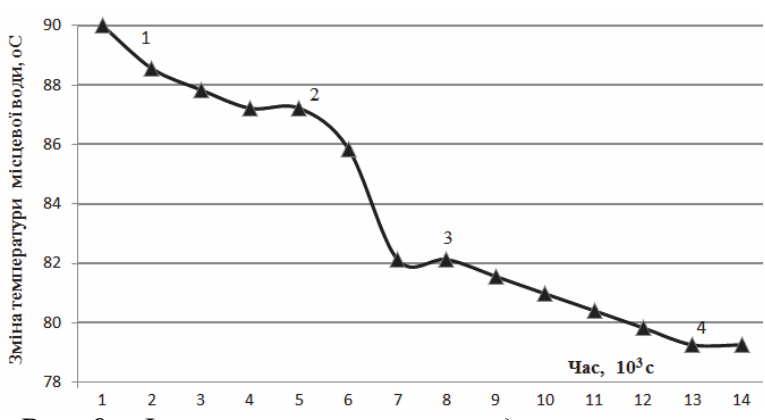

Рис. 9 - Інтегрована система підтримки температури місиевої води: 1-завантаження свіжої деревини; 2, 3 - підтримка сушки деревини щчодо переходу з першого рівня функиіонування на другий та з другого рівня функиіонування на третій, відповідно; 4 - відвантаження висушеної деревини

Так, наприклад, рівень підтримки зміни температури місцевої води 1 (рис. 9) забезпечує підігрів 1,8 кг/с повітря в термін часу від завантаження свіжої деревини до підігріву повітря до $82{ }^{\circ} \mathrm{C}$ [10]. Прийняття рішення на зменшення частоти обертання двигуна повітряного вентилятора щодо зміни витрати повітря, що подається на підігрів 3 1,8 кг/с до 1,68 кг/с [10] відповідає зниженню температури газів на вході з теплообмінник другого контуру когенераційної системи $3140{ }^{\circ} \mathrm{C}$ до $134{ }^{\circ} \mathrm{C}$ та зниженню температури зворотної води з $60^{\circ} \mathrm{C}$ до $56^{\circ} \mathrm{C}$. В цей термін часу прийнято рішення на зміну кількості пластин теплообмінника з 36 на 44 щодо входження в допуск рівня функціонування 2 (рис. 9) когенераційної системи для підтримки температури місцевої води, що подається на підігрів повітря. При подальшому зменшенню частоти обертання електродвигуна повітряного вентилятора впродовж терміну сушки деревини та відповідному прийняттю рішень на зміну витрати повітря на підігрів [10] здобута інтегрована система зміни температури місцевої води (рис. 9) дозволяє на основі прийняття рішень на зміну кількості пластин теплообмінника виконувати зміну рівня функціонування 2 на рівень функціонування 3. В термін часу 13200 с при температурі повітря, що подається на підігрів, на рівні $74{ }^{\circ} \mathrm{C}$ [10] прийняття рішення на відвантаження висушеної деревини відповідає зміні температури газів на вході в теплообмінник другого контуру когенераційної системи $120{ }^{\circ} \mathrm{C}$ та температурі зворотної води $-55^{\circ} \mathrm{C}$, що підтримує завершення процесу сушки деревини 3 використанням рівня функціонування 4 (рис. 9) та надає можливість входження в допуск рівня функціонування 1 щодо зміни кількості пластин теплообмінника 352 до 36 для підтримки підігріву повітря щодо сушки завантаженої свіжої деревини (рис. 9).

\section{Обговорення результатів}

В результаті проведених досліджень на основі запропонованої архітектури когенераційної системи виконано комплексне математичне моделювання динаміки теплообмінника другого контуру підігріву місцевої води при вимірюванні температури газів та температури зворотної води на вході в теплообмінник. Визначено граничну зміну температури місцевої води для встановлених рівнів функціонування когенераційної системи. Розроблено системи контролю працездатності когенераційної системи щодо підтримки зміни температури місцевої води для фіксованого інтервалу часу. Розроблено інтегровану систему підтримки температури місцевої води при вимірюванні температури газів на вході в теплообмінник та температури зворотної води щодо зміни калькості пластин теплообмінника впродовж сушки деревини при встановленому терміну відвантаження висушеної деревини та завантаження свіжого матеріалу. Забезпечено підтримку співвідношення виробництва електричної енергії та теплоти, що при безперервному функціонуванні когенераційної системи, надає можливість додаткового вироблення енергії. Представлені дослідження, що $\epsilon$ продовженням роботи в напрямку узгодження виробництва та споживання біопалива $[2,10]$, можуть бути апробовані для когенераційних систем різної потужності.

\section{Висновки}

В результаті проведених досліджень встановлено, що:

1) Виробництво пелетного палива у складі когенераційної системи потребує підтримки співвідношення виробництва електричної енергії та теплоти при використанні зміни частоти обертання електродвигуна повітряного вентилятора щодо зміни витрати повітря, що подається на підігрів, для сушки деревини.

2) Запропоновано архітектуру когенераційної системи, що має у своєму складі основу - динамічну підсистему, яка включає когенераційну 
установку, теплообмінник другого контуру підігріву місцевої води, сушильну установку, теплообмінник підігріву повітря, повітряний вентилятор та блоки розряду, заряду, оцінки функціональної ефективності, що знаходяться в узгодженій взаємодії з динамічною підсистемою.

3) Виконано комплексне математичне моделювання динаміки теплообмінника другого контуру підігріву місцевої води при вимірюванні температури газів та температури зворотної води на вході в теплообмінник. Визначено граничну зміну температури місцевої води для встановлених рівнів функціонування на основі розробленої структурної схеми.

4) Виконано контроль працездатності та підтвердження нових умов функціонування когенераційної системи на основі здобуття функціональної оцінки зміни температури місцевої води в умовах зміни витрати повітря на підігрів для сушки деревини.

5) Розроблено структурну схему та виконано підтримку температури місцевої води на рівні прийняття рішень. Особливістю цієї схеми є порівняння температури газів на вході в теплообмінник, що вимірюється, 3 еталонним значенням та визначення підсумкової інформації щодо прийняття рішень.

6) Розроблено інтегровану систему підтримки температури місцевої води при вимірюванні температури газів на вході в теплообмінник та температури зворотної води щодо зміни калькості пластин теплообмінника та забезпечення підтримки відвантаження висушеної деревини та завантаження свіжого матеріалу.

7) Підтримка співвідношення виробництва електричної енергії та теплоти надає можливість наприклад, в умовах функціонування когенераційної системи номінальною потужністю 115 кВт при виробництві 5,8 тис. т пелет 3 деревини в рік знизити собівартість виробництва енергії в межах $20-30 \%$.

\section{Список літератури}

1 Гелетуха, Г. Г. Биоэнергетика в Украине: современное состояние и перспективы развития. Часть $2 /$ Г. Г. Гелетуха, Т. А. Железная, П. П. Кучерук, Е. Н. Олейник, А. В. Трибой // Промышленная теплотехника. - 2015. - Т. 37, № 3. - С. 65-73. - ISSN 0204-3602.

2 Чайковська,, . С. Розробка енергозберігаючої технології підтримки функціонування біодизельної установки у складі когенераційної системи / Є. С. Чайковська // Восточно-Европейский журнал передовых технологий. - 2016. - № 1/8(79). - С. 4 11. - ISSN 1729-3774. - doi: 10.15587/17294061.2016.59479.

3 Трошин, А. Г. Развитие процессов и оборудования для производства топливных брикетов из биомассы /
А. Г. Трошин,
В. Ф. Моисеев,
И. А. Тельнов,

С. И. Завинский // Восточно-Европейский журнал передовых технологий. - 2010. - № 8/45(3). - С. 3640. - ISSN 1729-3774.

4 Bhattarai, Sujala. Simulation Study for Pneumatic Conveying Drying of Sawdust for Pellet Production / Sujala Bhattarai, Jae-Heun Oh, Seung-Hee Euh, Dae Hyun Kim, Liang Yu // Drying Technology. - 2014. Vol. 32. - p. 1142-1156. - ISSN 0737-3937. - doi: 10.1080/07373937.2014.884575.

5 Laurila, Jussi. Compression drying of energy wood / Jussi Laurila, Havimo Mikko, Lauhanen Risto // Fuel Processing Technology. - 2014. - Vol. 124. p. 286-289. - ISSN 0378-3820. - doi: 10.1016/j.fuproc.2014.03.016.

6 Yuping, Liu. Application of the self-heat recuperation technology for energy saving in biomass drying system / Liu Yuping, Aziz Muhammad, Kansha Yasuki, Bhattacharya Sankar, Tsutsumi Atsushi // Fuel Processing Technology. - 2014. - Vol. 117. - p. 66-74. - ISSN 0378-3820. - doi: 1016/j.fuproc.2013.02.007.

7 Wang, Hai-tao. Study of Immune PID Controller for Wood Drying System / Hai-tao Wang, He-ming Jia // 2013 International Conference on Communication Systems and Network Technologies. - 2013. - p. 827831. - ISBN 1-4673-5603-9. - doi: 10.1109/csnt.2013.176.

8 Zhongfu, Tian. Research on control system of wood drying based on BP Neural Network / Tian Zhongfu, Li Yuehua // Proceedings 2013 International Conference on Mechatronic Sciences, Electric Engineering and Computer(MEC). - 2013. - p. 36-38. - ISBN 44799-2564-3. - doi: 10.1109/mec.2013.6885046.

9 Perre, Perre. Drying of Wood: Principles and Practices / Patrick Perre, Roger Keey // Handbook of Industrial Drying. - 2014. - p. 797-846. - ISSN 978-1-46659665-8. - doi: 10.1201/b17208-44.

10 Чайковська, С. С. Development of energy-saving technology maintaining the functioning of a drying plant as a part of the cogeneration system / Є. Є. Чайковська // Восточно-Европейский журнал передовых технологий. - 2016. - Т. 3, № 8(81). - С. 42-46. - ISSN 1729-3774. - doi: 10.15587/17294061.2016.72540

\section{Bibliography (transliterated)}

1 Heletuha, H. H., Gelieznaia, T. A., Kuchtruk, P. P., Olienic, E. N. and Triboi, A. B. (2015), "Bioenergetika $\mathrm{v}$ Ukraine : sovremennoe sostojnie $\mathrm{i}$ perspective razvitija. Chast' 2 [Bioenergy in Ukraine: Current State and Prospects for Development. Part 2]", Promyshlennaja teplotechnika [Industrial Heat Engineering], No. 3(37), pp. 65-73, ISSN 0204-3602.

2 Chaikovskaya, E. E. (2016), "Rozrobka energozberigajuchoi technologii pidtrimki bidizelnoi ustanovki u skladi kogeneracijnoi sistemy [The development of energy-saving technology support operation of biodiesel plant of the composition of cogeneration system]", Vostochno-Evropejskij zhurnal peredovich technologij [Eastern-European Journal of Enterprise Technologies], No. 1/8(79), pp. 4-11, ISSN 1729-3774, doi: 10.15587/1729-4061.2016.59479.

3 Trohin, A. H., Moisiev, V. F., Telnov, I. A. and Zavinski, S. I. (2010), "Razvije processov I oborudovanij dlja proizvodstva toplivnih briketov iz biomassy [Development of processes and equipment for the production of fuel pellets from biomass]", Vostochno- 
Evropejskij zhurnal peredovich technologij [EasternEuropean Journal of Enterprise Technologies], No. 8/45(3), pp. 36-40, ISSN 1729-3774.

4 Bhattarai Sujala, Jae-Heun Oh, Seung-Hee Euh, Dae Hyun Kim, Liang Yu(2014), "Simulation Study for Pneumatic Conveying Drying of Sawdust for Pellet Production", Drying Technology, No. 32, pp. 1142-1156, ISSN 0737-3937, doi: 10.1080/07373937.2014.88457.

5 Jussi Laurila, Havimo Mikko, Lauhanen Risto (2014), "Compression drying of energy wood", Fuel Processing Technology, No. 124, pp. 286-289, ISSN 0378-3820, doi: 10.1016/j.fuproc.2014.03.016.

6 Liu Yuping, Aziz Muhammad, Kansha Yasuki, Bhattacharya Sankar, Tsutsumi Atsushi (2014), "Application of the self-heat recuperation technology for energy saving in biomass drying system", Fuel Processing Technology, No. 117, pp. 66-74, ISSN 0378-3820, doi: 1016/j.fuproc.2013.02.007.

7 Hai-tao Wang, Heming Jia (2013), "Study of Immune PID Controller for Wood Drying System", 2013 Interna- tional Conference on Communication Systems and Network Technologies, pp. 827-831, ISBN 1-4673-5603-9. - doi: 10.1109/csnt.2013.176.

8 Zhongfu, Tian, Li Yuehua (2013), "Research on control system of wood drying based on BP Neural Network" Proceedings 2013 International Conference on Mechatronic Sciences, Electric Engineering and Computer(MEC), pp. 36-38, ISBN 4-4799-2564-3, doi: 10.1109/mec.2013.6885046.

9 Patrick Perre, Roger Keey (2014) "Drying of Wood: Principles and Practices", Handbook of Industrial Drying, pp. 797-846, ISSN 978-1-4665-9665-8, doi: 10.1201/b17208-44.

10 Chaikovskaya, E. E. (2016), "Development of energysaving technology maintaining the functioning of a drying plant as a part of the cogeneration system", EasternEuropean Journal of Enterprise Technologies, No $3 / 8(81)$, pp. 42-46, ISSN 1729-3774, doi: 10.15587/1729-4061.2016.72540.

\section{Відомості про автора (About author)}

Чайковська Євгенія Євстафіївна - кандидат технічних наук, старший науковий співробітник, Одеський національний політехнічний університет, доцент кафедри теоретичної, загальної та нетрадиційної енергетики; м. Одеса, Україна; e-mail: eechaikovskaya@gmail.com, ORCID 0000-0002-5663-2707.

Chaikovskaya Eugene - Candidate of Technical Sciences (Ph.D.), Senior Researcher, Odessa National Polytechnic University, Associate Professor, Department of Theoretical, general and alternative energy, Odessa, Ukraine.

Будь ласка посилайтесь на июю статтю наступним чином:

Чайковська, Є. Є. Контроль працездатності когенераційної системи на пелетному паливі / Є. Є. Чайковська // Вісник НТУ «ХПІ». Серія: Енергетичні та теплотехнічні процеси й устаткування. - Харків : НТУ «ХПІ», 2017. № 11(1233). - С. 87-94. - Бібліогр.: 10 назв. - ISSN 2078-774X. - doi: 10.20998/2078-774X.2017.11.14.

Please cite this article as:

Chaikovskaya, E. (2017), "Control Working Ability of the Cogeneration System on Pellet Fuel", Bulletin of NTU "KhPI". Series: Power and heat engineering processes and equipment, No. 11(1233), pp. 87-94, ISSN 2078-774X, doi: 10.20998/2078-774X.2017.11.14

Пожалуйста ссылайтесь на эту статью следуюшим образом:

Чайковская, Е. Е. Контроль работоспособности когенерационной системы на пеллетном топливе / Е. Е. Чайковская // Вісник НТУ «ХПІ». Серія: Енергетичні та теплотехнічні процеси й устаткування. - Харків : НТУ «ХПІ», 2017. - № 11(1233). - С. 87-94. - Бібліогр.: 10 назв. - ISSN 2078-774X. - doi: 10.20998/2078774X.2017.11.14.

АННОТАЦИЯ Предложена интегрированная система поддержания температуры местной воды при измерении температуры газов и температуры обратной воды на входе в теплообменник второго контура когенерационной системы. Принятие решений на изменение количества пластин теплообменника позволяет поддерживать соотношение производства электрической энергии и теплоты при использовании изменения частоты врашения электродвигателя воздушного вентилятора для изменения расхода воздуха, подающегося на подогрев для сушки древесины. Такой подход позволяет, например, в условиях функиионирования когенерационной системы мощностью 115 кВт снизить себестоимость выработанной энергии до 20-30\%.

Ключевые слова: когенерационная установка, пеллетное топливо, контроль работоспособности, принятие решений. 